\title{
Structural effects of atypical antipsychotics: Implications for the meaning of cortical volume deficit in schizophrenia
}

\author{
Vicente Molina*, PhD \\ * Dept of Psychiatry, Hospital Clínico de \\ Salamanca, Salamanca \\ SPAIN
}

\begin{abstract}
Patients with schizophrenia have a smaller volume of cortex than healthy controls. Nevertheless, the substrate of such deficit is not well understood A progressive loss of cortical GM in schizophrenia seemed supported by early studies with magnetic resonance imaging (MRI) in which patients received typical drugs between the baseline and final scans. However, recent MRI results challenge this notion and suggest that structural changes may depend, at least in part, on the type of treatment received. These data may be relevant for a correct interpretation of the substrate of cortical volume deficit in schizophrenia. If that deficit can be even reversed by treatment, as suggested by recent studies, a neuronal substrate seems unlikely. Several lines of evidence instead support that glia cells may have a role in cortical structural and functional deficits in schizophrenia, which would be also in agreement with recent longitudinal results with MRI in patients treated with atypical antipsychotics. These evidences are reviewed in this paper.
\end{abstract}

\section{Introduction}

After several decades of intensive research, it is accepted that patients with schizophrenia (SZ) as a group have a smaller volume of cortex than healthy controls (Shenton et al. 2001). Nevertheless, the substrate of such deficit is not well understood although a deficit in the number of neurons sems not explain it (Selemon et al. 1999a).

Neuropathology is needed to clarify the basis of that cortical deficit, but this kind of studies in SZ are subject to powerful confounding factors (medication, social isolation, toxic consumption and post-mortem interval among others). These factors may obscure the interpretation of data, even more if we consider that the volume deficit attributable to $\mathrm{SZ}$ is quantitatively small (Woods et al. 2005).

Magnetic resonance imaging (MRI), in this context, can yield complementary results to neuropathology. There are at least two questions of great relevance for the meaning 
of cortical volume deficits in SZ that longitudinal MRI studies may answer: the temporal progression of volume deficits and the effect of different antipsychotics on it.

\section{Effect of the type on antipsychotic on the outcome of cortical deficit}

Early longitudinal studies using MRI in SZ described an accelerated decrease of gray matter (GM) volume in cerebal hemispheres and cerebellum (DeLisi et al. 1997), frontal (Gur et al. 1997, Mathalon et al. 2001) and temporal (Mathalon et al. 2001) lobes, and hippocampus (Lieberman et al. 2001) as compared to controls. Besides, a faster rate of ventricular (DeLisi et al. 1997, Lieberman et al. 2001, Mathalon et al. 2001, Nair et al. 1997) and frontal sulcal (Mathalon et al. 2001) spaces enlargement has also been described. Such volume changes have been viewed as a possible correlate of neuronal tissue loss although other factors may contribute to the GM changes evidenced by MRI. In these early studies, patients received typical antipsychotics (TA) during the follow-up period. In similar populations, also treated with TA, a significant association was noted between illness duration and the excess of volume in frontal and temporal sulcal cerebrospinal fluid spaces (Molina et al. 2002, Turetsky et al. 1995), suggesting a sustained progression of GM loss in that areas, filled up with cerebrospinal fluid. Finally, an inverse association between the frontal signal of $\mathrm{N}$-acetylaspartate, considered a marker of the amount of viable neuronal tissue (Urenjak et al. 1993) and disease duration (Ende et al. 2000, Molina et. al. 2005c) has also been found, but not in patients with longer chronicity (Block et al. 2000, Deicken et al. 1997, Lim et al. 1998). These data, as a whole, support a progession of the GM deficit in patients treated with TA.

However, more recent results challenge this notion and suggest that cortical changes may depend, at least in part, on the type of treatment received, as previoulsy demonstrated in basal ganglia (Chakos et al. 1995). This new generation of studies coincides with the generalized use of atypical antipsychotics (AA) in SZ. Ho et al. did not find significant changes of cortical GM in 73 patients after a mean follow-up of 3 years (Ho et al. 2003). In this sample, 20 out of the 38 patients who received treatment during the whole follow-up period received only AA. Besides another group did not find significant changes in the outcome of hemispheric volumes between controls and SZ patients (13 receiving AA, 6 TA and 7 without treatment), after a 10 years of follow-up (DeLisi et al. 2004). Finally, another study in first-episode adults described frontal and temporal GM deficits in patients treated with TA for 8 weeks $(n=32)$ compared to untreated patients $(n=22)$, while another group of patients treated with AA $(\mathrm{n}=30)$ presented a thalamic GM excess with no cortical deficit compared to the same untreated group (Dazzan et al. 2004). There is however not complete agreement on this. Another group a significant decrease in brain volume (1.2\%) and cerebrum $(2.9 \%)$, and a enlargement of ventricles $(7.7 \%)$ described in the year following a first psychotic episode in patients treated with a variety of TA and AA, alone or in combination (Cahn et al. 2002a).

From these studies, it seems likely that greater rates of GM decrease can be found when treatment between scans consisted of TA. This is specially supported by the reversion of the previous GM volume deficits reported by two groups. Keshavan et al. (1998) have reported that the superior tem- 
poral gyrus volume deficit may reverse with treatment in first SZ episodes, without describing the kind of treatment the patients received during follow-up. Moreover, Molina et al. (in press a) studied two groups of SZ patients (first episodes and treatment chronic resistant cases) at baseline and after two years of treatment, respectively with risperidone and clozapine. In this study, in both groups a significant increase of GM was found in parietal (mean chronic $7.3 \%$, first episodes $1.2 \%$ ) and occipital (mean chronic $14.9 \%$, first episodes $6.2 \%$ ) regions, after correcting for changes in intracranial volume between scans. Frontal GM also increased in the chronic group with clozapine (mean 6.8\%). These authors calculated a quantitative measure (residuals) representing the volumetric differences in GM and WM as compared to controls. Both groups showed a significant GM deficit, more marked and extended in the chronic group. There was a significant inverse relationship between the baseline deficit and the longitudinal change (Figure 1). In another study of frontal GM changes in adolescents with SZ $(\mathrm{n}=16$, mean age at baseline $=18)$, an increase of $1.9 \%$ after 2 years of treatment with atypical drugs was reported (James et al. 2004). A sharp difference in the outcome of the brains in these patients seems therefore to depend on the type of treatment used, which is specially supported by the recent report of Lieberman et al. (2005). In a wide sample of first episodes, they studied the differences in outcome of the brain MRI measures between patients receiving haloperidol or olanzapine during follow-up. Haloperidol-treated patients exhibited significant decreases in gray matter volume, whereas olanzapine-treated patients did not.

These results have potentially important implications for the meaning of the volume deficits of GM found in SZ. The "dynamic" properties (its changes along time) of the structural deficits may give relevant clues for its correct interpretaion. For example, if these deficits can be reversed by treatment, as suggested by recent results (James et al. 2004, Keshavan et al. 1998, Molina et al. in press a), are unlikely due to a neuronal number decrease. Other cellular (or non-celular) elements in the brain with a plasticity reserve such than can be reflected in MRI studies can account for the treatment-related increase and also perhaps for the corresponding baseline volume deficits. Besides, if the outcome of the brain structure depends on the type of treatment received between MRI scans, we can wonder if typical drugs are neurotoxic and/or atypical drugs are "neuroprotective".

\section{Neurotoxic or neuroprotective effects of antipsychotics?}

The debate around the possible neurotoxcity of antipsychotics is old, and yet unresolved. The outcome of patients in the neuroleptic era is better than in the previous one, which would be compatible with a protective role for antipsychotics against cerebral alterations.

Different arguments support the opposite views of a neurotoxic and a neuroprotective role of antipsychotic drugs. In support of the first position, results obtained in preclinical models support a neurotoxic profile for TA. It has been reported that these antipsychotics can induce neuronal apoptosis (Noh et al. 2000) or reduce synaptic density (Kelley et al. 1997). A decrease in brain-derived neurotrophic factor has also been reported in association with neuroleptic treatment (Angelucci et al. 2000). Moreover, a recent study performed in monkeys suggests that chronic exposure to haloperidol and olanza- 
pine may decrease brain weight and volume (Dorph-Petersen et al. 2005). In a this study, macaque monkeys were administered with haloperidol or olanzapine for 17 to 27 months to investigate the macroscopic effects of antipsychotics on the brain. They found that both treatments, given at higher doses than usual in humans, produced a slight, but significant, decrease in brain
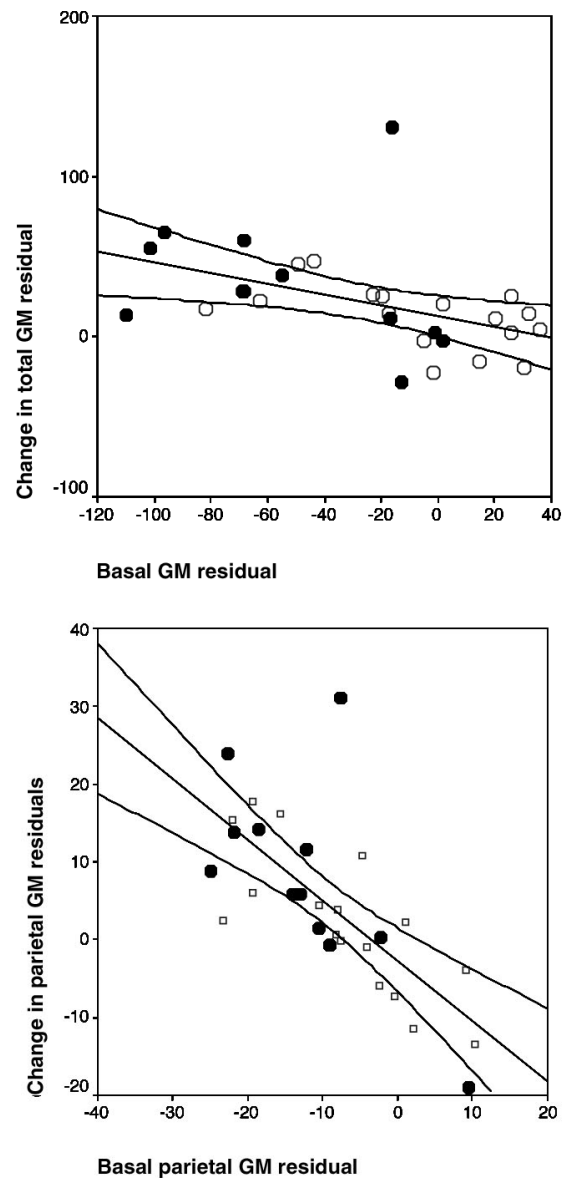

weight and volume, more pronounced in the frontal and parietal regions.

As these studies were preclinical, we cannot conclude that the human brain would show the same changes in the case of cerebral illness. It seems therefore important to assess the effects of neuroleptics in the brain structure of SZ patients, and neuroimaging offers the possibility to do so.
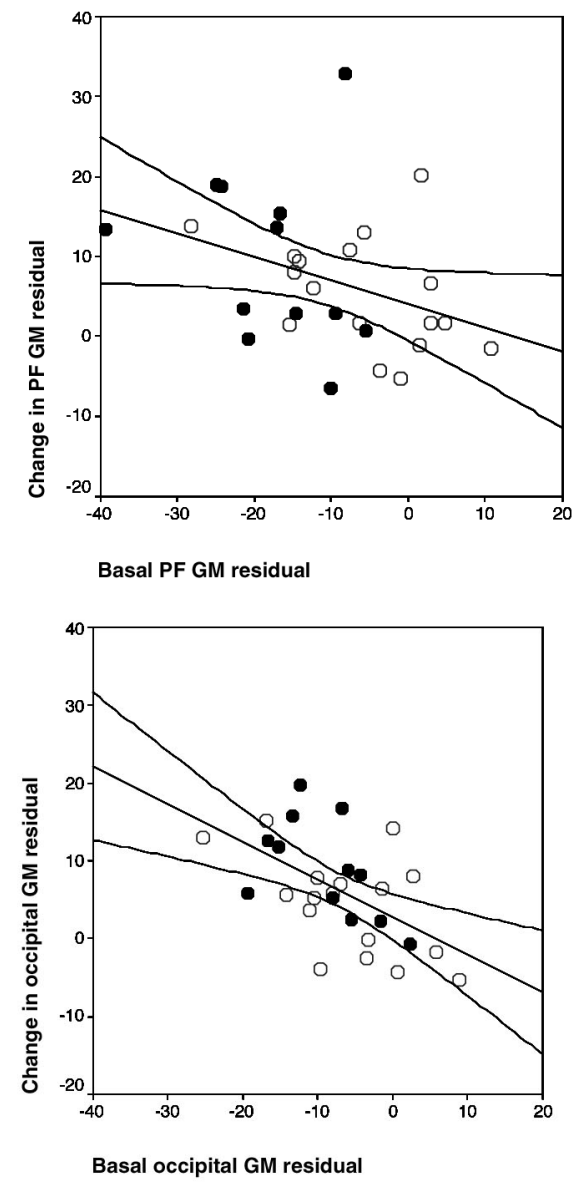

Figure 1. Relationship between the prior degree of atrophy and the longitudinal change in GM (hollow dots: CR group, solid dots: NN group). The $\mathrm{X}$-axis shows the baseline atrophy / hypertrophy value and the Y-axis the corresponding longitudinal changes (see Molina et al. in press a for details). Values in $\mathrm{X}$ and $\mathrm{Y}$ axis are expressed in cubic centimeters. 
This possibility has been explored by assessing the relation between cumulative dosage of antipsychotics and changes in MRI scans. Results are discrepant: on the one hand, an association between GM loss and cumulative dosage was reported (Cahn et al. 2002b, Madsen et al. 1999). On the other hand, it has been also reported that higher cumulative exposure to TA is associated with lower ventricular enlargement (DeLisi et al. 1997, Lieberman et al. 2001), coherent with a lower rate of gray matter decrease. These studies were performed in samples treated with TA, except for that of Cahn et al. (2002b), with patients receiving TA or any of 5 different AA. Besides, as previously mentioned, volumetric deficit in STG may even reverse with treatment (Keshavan et al. 1998). These discrepancies between MRI studies may relate to several factors. For instance, some patients may require higher dosages due to a more severe illness form, that may producer greater brain changes. Morevoer, ventricular enlargement does not reflect exactly the same process than volumetric GM changes.

At this point, it is necessary to distinguish between TA and AA when it comes to determining the possible effect of neuroleptics on alterations in cortical volume. Its effects on brain structure and function are clearly different. It has been reported that clozapine has an effect of reversing increases in basal ganglia volume induced by TA (Chakos $e t$ al. 1995). It has also been found that AA do not produce an increase in basal ganglia volume in treatment-naïve patients (Heitmiller et al. 2004), which is a known effect of TA (Bartlett et al. 1994, Buchsbaum et al. 1987, DeLisi et al. 1985, Holcomb et al. 1996). Furtehermore, AA have a greater capacity than TA for increasing NAA levels in the prefrontal (PF) cortex (Bertolino et al. 2001). Finally, as previously mentioned, recent longitudinal MRI studies using exclusively AA between scans have shown the absence on GM volume loss with olanzapine (Lieberman et al. 2005) and the gain of cortical GM volume with risperidone and clozapine, proportional to the pre-existing deficit (Molina et al. in press a). AA, or at least some AA, may thus exert a different effect on cortical volumes than TA. The observation by Cahn et al. (2002b) that patients treated, in part, with AA (clozapine, olanzapine, risperidone, sertindole or quetianpine) also showed an accelerated volume loss may contradict this idea. However, the results of these author could be due to a different structural effect among "AA", as in our previous study differences between the anatomical effects of risperidone and clozapine were noted (Molina et al. in press a). Moreover, olanzapine did not produce GM gain, but a "detention" of loss (Lieberman et al. 2005).

\section{What do we know about the basis of the structural effects of antipsychotics?}

In theory, the first possibility would be that the lower rate of GM loss (or even GM gain) observed with AA were related to neurogenesis. This was supported by the report of a 2- to 3-fold increase in newly divided cells in the subventricular zone in the rat with AA. Some of these new cells in the subventricular zone and hippocampus also expressed a neuronal marker (Wakade et al. 2002). Another study showed that clozapine induced cell division in hippocampus, though the resulting neurons did not survive 3 weeks later (Halim et al. 2004). Then, although some neurogenesis may not be discarded with AA, it does not seem relevant in the cortex, and cells may not survive. Moreover, in primate cortex there was no 
increase of neuronal tissue after treatment with TA or AA neuroleptics (Selemon et al. 1999b). Thus, it seems unlikely that the increase of GM with AA is caused by the appearance of new neurons.

Another possibility is synaptogenesis. There is good evidence to support synaptogenesis by TA (Konradi et al. 2001), a factor that migh contribute to the observed striatal enlargment induced by these drugs (Chakos et al. 1994). This enlargement coincides with a regional increase in metabolic activity (Bartlett et al. 1994, Buchsbaum et al. 1987, DeLisi et al. 1985, Holcomb et al. 1996), an expected correlate of synaptogenesis if we assume a direct association between synaptic activity and the signal detected by functional imaging (Jueptner $e t$ al. 1995).

The possibility that AA might induce synaptogenesis in the cortex to explain its particular anatomical effects is attractive in the light of the theories of reduced cortical connectivity in SZ (McGlashan et al. 2000). Formation of new neuronal elements such as synapses, seems in any case more likely than neurogenesis in the adult brain. Nevertheless, as previously stated, the absence of neuronal tissue increase in primate cortex after AA seems incompatible with such explanation (Selemon et al. 1999b). Moreover, a huge increase of connections would be required to explain a GM volume increase susceptible of being detected with MRI. Finally, treatment with AA do not produce a marked metabolic increase in the cortex (Cohen et al. 1997, Lahti et al. 2003a, Lahti et al. 2003b, Miller et al. 2001, Molina et al. 2003, Molina 2005a, Molina 2005 b), at least to the degree produced by classicals in the basal ganglia. These reasons make unlikely that an increase of connections justifies the distinct structural effects of AA.
If we consider unlikely an action on neurons to explain the possible volumetric effect of AA, we can wonder if such morphological effect can take place through glial cells. Several findings support this possibility.

First, glial cell loss may be significant in $\mathrm{SZ}$, at least in some regions (Cotter et al. 2001b, Stark et al. 2004). Numerical density of oligodendrogial cells may be reduced by a $25 \%$ in prefrontal areas in SZ (Uranova et al. 2001). According to these Stark et al. (2004), a 33\% decrease (statistically significant) in gliall cells was observed in the anterior cingulate region. The possibility of a role for glia in SZ is also supported by reports of decreased glial fibrillary acidic protein-(GFAP), a protein specific of astrocytes in that illness (Johnston-Wilson et al. 2000, Rajkowska et al. 2002). GFAP immunoreactive astroglia in the prefrontal cortex in SZ was reported to be decreased by a significant $32 \%$ in the GFAP-area fraction, together with a $14 \%$ decrease in the width of the cortical layer $\mathrm{V}$, as compared to the control subjects. None of these parameters were affected in layers III and IV in the patients. It may be investigated if such deficit relates to the structural deficit in SZ.

Second, proliferation of glial cells along with cortical hypertrophy has been observed in the prefrontal cortex of primates after treatment with AA (Selemon et al. 1999b). Besides, olanzapine can increase the number of dividing glial cells in the frontal cortex of the adult rat (Wang et al. 2004).

In our previous study (Molina et al. in press a), pre-existing volume deficits were found associated in first episodes and chronic patients with the increases in cortical volume respectively induced by risperidone and clozapine (Figure 1). Thus, if replicated, an association between the sus- 
trate of cortical volume deficit and that of structural change induced by AA is suggested. In other words, an hypothetical interpretation of longitudinal MRI data would be that cortical volume deficit in SZ could be contributed by a glial deficit.

\section{Changes in WM with AA}

One of the most puzzling results of our mentioned study (Molina et al. in press a) was the co-occurrence in this sample of GM

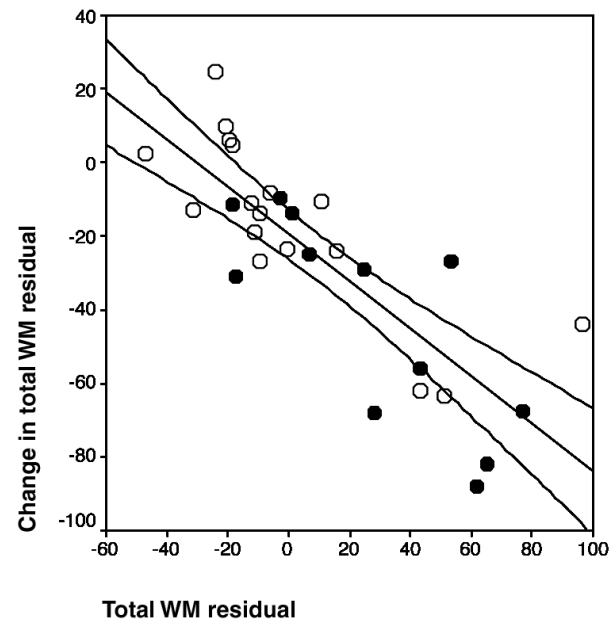

increase and decrease in WM (Figure 2). Both changes were however statistically unrelated, suggestionfg that, although coincident in time, had a different substrate. The WM volume decrease was not reported in longitudinal studies where patients had been treated with TA, but is consistent with the recent finding of a decrease in WM after four weeks of TA or AA treatment (Christensen et al. 2004). That WM decrease with AA can be of interest, given the data supporting that WM volume may indeed be increased in SZ (Lawrie et al. 1998).

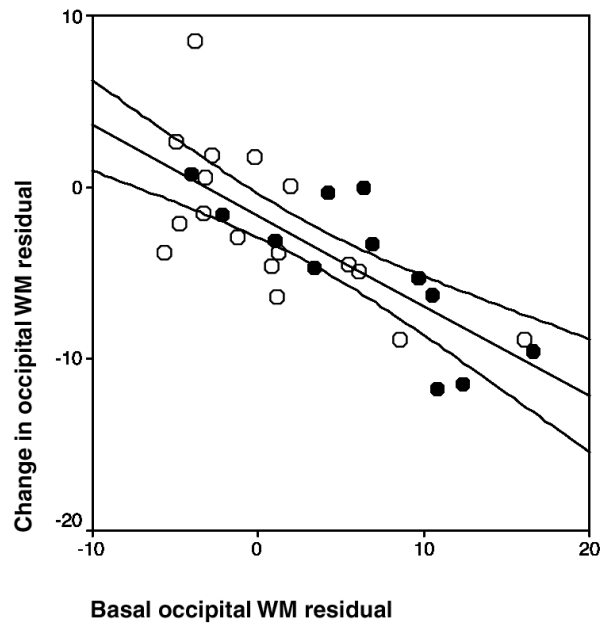

Figure 2. Relationship between the baseline deficit / hypertrophy in total and occipital WM and its longitudinal change in the two groups of patients. The $\mathrm{X}$-axis shows the baseline atrophy / excess and the $\mathrm{Y}$ axis the correponding longitudinal changes (see Molina et al. in press a for details). Values in $\mathrm{X}$ and $\mathrm{Y}$ axis are expressed in cubic centimeters.

If WM, in terms of volume is mostly formed by glial cells, how it comes that WM volume may decrease, with AA if we propose that GM volume gain was related to previously diminished glia? There is one plausible explanation for both findings (GM gain and WM loss) at expense of glial mechaninsms. Astrocytes predomine in GM and have an important role in synaptic func- tions, while oligodendrocytes predomine in $\mathrm{WM}$ and mainly form myelin sheats (Pfrieger et al. 1996). These two types could be differently affected by AA. For instance, the decrease in WM due to AA could be explained by a blockade of factors stimulating myelin synthesis. Such a factor could have to do with a chronic glutamatergic hyperactivation state since hyperactivity 
relates to increased myelination in other disease states (Adamsbaum et al. 1996, Krishnan et al. 1994). Such an hyperactivity state might be present in SZ (Molina et al. 2005d, Volk et al. 2002). This possibility would be consistent with the observation that oligoddendrocytes may be reduced in GM but not in adjacent WM in post-mortem data of patients treated with TA (Uranova et al. 2004). The metabolic down-regulation induced by clozapine in the frontal cortex in SZ patients (Cohen et al. 1997, Lahti et al. 2003b, Molina et al. 2005b) may be consistent decrease that hyperactive state, thus reducing myelin synthesis and WM volume. Although a similar effect has been reported for classical drugs (Holcomb et al. 1996), this effect may be more pronounced with clozapine (Molina et al. 2005b). At the same time, GM astrocytes may increase, by an unknown mechanism, as shown by the results in monkeys (Selemon et al. 1999b).

\section{Discussion}

Longitudinal MRI results in samples of SZ patients tend to support that, while on TA, an accelerated decrease of GM volume can be found. This may be an effect of treatment. However there is no evidence of neuron loss in patients treated for decades with these drugs (Selemon et al. 1999a), so we cannot conclude that TA are properly neurotoxics. The GM loss is not generally found in samples that received AA (alone or in combination with TA).

To explain this difference two possibilities arise: AA exert some compensation of illness-related problems or, AA simply do not cause the anatomical problems that TA would cause. The first possibility is more likely, as supported by the presence of anatomical deficits already in first episodes of SZ (Hirayasu et al. 2001, Molina et al. in press b, Nopoulos et al. 1995, Salokangas et al. 2002) and by the similar changes induced in this cases by AA than in chronic patients (Molina et al. in press a). In this context, we may pressume that longitudinal studies on classical antipsychotics would show more GM loss perhaps beacause of a lesser effect on illness-related factors. It cannot be discarded, however, some direct effect of TA on brain structure, as MRI images provide only limited information about underlying changes.

Certain AA may have an effect on preexisting deficit, as suggested by the association shown in Figures 1 and 2, together with other evidences mentioned in previous sections, let pressume a role for glia in SZ. Such a role may not simply have anatomical consequences. Glial cells are now accepted to have roles in providing trophic support to neurons, neuronal metabolism, and the formation of synapses and neurotransmission (Pfrieger et al. 1996). Thus, a glial deficit may have important functional consequences, that can be reflected in functional imaging and the subtle neuropsychological problems in SZ. In this direction, an effect of AA on glial cells would agree with the increase of brain occipito-visual activity (Molina et al. 2005b, Molina et al. 2003), observed in patients partially overlapping with those of the longitudinal MRI study (Molina et al. in press a), given the role of glial cells in PET data (Magistretti et al. 2000).

The involvement of glia may be not specific of SZ, as may be also found in mood disorders (Cotter et al. 2001a, Ongür et al. 1998). This inespecificity may have to do with the findings that white matter endophenotypes associated with SZ and bipolar disorder are overlapping (McDonald et al. 2004). 
In summary, the interpretation of recent longitudinal studies in SZ points to new lines of research. Following Berhard Bogerts (1983) 'If the functional unit of the brain is not the neuron but rather the neuron-glial complex, then both neuronal and glial cells could be involved in mental diseases'. Adequate studies are needed to test the suggestions made by these interpretations.

\section{References}

Adamsbaum C, Pinton F, Rolland Y, Chiron C, Dulac O, Kalifa G. Accelerated myelination in early Sturge-Weber syndrome: MRI-SPECT correlations. Pediatr Radiol 1996; 26: 759-762.

Angelucci F, Mathe AA, Aloe L. Brain-derived neurotrophic factor and tyrosine kinase receptor TrkB in rat brain are significantly altered after haloperidol and risperidone administration. J Neurosci Res 2000; 60: 783-794.

Bartlett EJ, Brodie JD, Simkowitz P, Dewey SL, Rusinek H, Wolf AP et al. Effects of haloperidol challenge on regional cerebral glucose utilization in normal human subjects. Am J Psychiatry 1994; 151: 681-686.

Bertolino A, Callicott JH, Mattay VS, Weidenhammer KM, Rakow R, Egan MF et al. The effect of treatment with antipsychotic drugs on brain $\mathrm{N}$-acetylaspartate measures in patients with schizophrenia. Biol Psychiatry 2001; 49: 3946.

Block W, Bayer TA, Tepest R, Traber F, Rietschel M, Muller DJ et al. Decreased frontal lobe ratio of $\mathrm{N}$-acetyl aspartate to choline in familial schizophrenia: a proton magnetic resonance spectroscopy study. Neurosci Lett 2000; 289: 147-151.

Buchsbaum MS, Wu JC, DeLisi LE, Holcomb HH, Hazlett E, Cooper Langston $\mathrm{K}$ et al. Positron emission tomography studies of basal ganglia and somatosensory cortex neuroleptic drug effects: differences between normal controls and schizophrenic patients. Biol Psychiatry 1987; 22: 479-494.

Cahn W, Pol HE, Bongers M, Schnack HG, Mandl RC, Van Haren NE et al. Brain morphology in antipsychoticnaive schizophrenia: a study of multiple brain structures. Br J Psychiatry 2002a; 43 (Suppl): s66-s72.
Cahn W, Pol HE, Lems EB, van Haren NE, Schnack $\mathrm{HG}$, van der Linden JA et al. Brain volume changes in firstepisode schizophrenia: a 1-year follow-up study. Arch Gen Psychiatry 2002b; 59: 1002-1010.

Cohen RM, Nordahl TE, Semple WE, Andreason P, Litman RE, Pickar D. The brain metabolic patterns of clozapine- and fluphenazine- treated patients with schizophrenia during a continuous performance task. Arch Gen Psychiatry 1997; 54: 481-486.

Cotter D, Mackay D, Landau S, Kerwin R, Everall I. Reduced glial cell density and neuronal size in the anterior cingulate cortex in major depressive disorder. Arch Gen Psychiatry 2001; 58: 545-553.

Cotter DR, Pariante CM, Everall IP. Glial cell abnormalities in major psychiatric disorders: the evidence and implications. Brain Res Bull 2001; 55: 585-595.

Chakos MH, Lieberman JA, Alvir J, Bilder R, Ashtari M. Caudate nuclei volumes in schizophrenic patients treated with typical antipsychotics or clozapine. Lancet 1995; 345: 456-457.

Chakos MH, Lieberman JA, Bilder RM, Borenstein M, Lerner G, Bogerts B et al. Increase in caudate nuclei volumes of first-episode schizophrenic patients taking antipsychotic drugs. Am J Psychiatry 1994; 151: 14301436.

Christensen J, Holcomb J, Garver DL. State-related changes in cerebral white matter may underlie psychosis exacerbation. Psychiatry Res 2004; 130: 71-78.

Dazzan P, Morgan K, Chapple B, Suckling J, Chitnis X, Fearon $\mathrm{P}$ et al. The effects of typical and atypical antipsychotics on brain structure in the AESOP first-onset psychosis study. Schizophrenia Res 2004; 67: 95.

Deicken RF, Zhou L, Schuff N, Weiner MW. Proton magnetic resonance spectroscopy of the anterior cingulate region in schizophrenia. Schizophr Res 1997; 27: 65-71.

DeLisi LE, Holcomb HH, Cohen RM, Pickar D, Carpenter W, Morihisa JM et al. Positron emission tomography in schizophrenic patients with and without neuroleptic medication. J Cereb Blood Flow Metab 1985; 5: 201-206.

DeLisi LE, Sakuma M, Maurizio AM, Relja M, Hoff AM. Cerebral ventricular change over the first 10 years after the onset of schizophrenia. Psychiatry Res: Neuroimaging 2004; 130: 57-70.

DeLisi LE, Sakuma M, Tew W, Kushner M, Hoff AL, Grimson R. Schizophrenia as a chronic active brain process: a study of progressive brain structural change subsequent to the onset of schizophrenia. Psychiatry Res 1997; 74: 129-140.

Dorph-Petersen KA, Pierri JN, Perel JM, Sun Z, Sampson AR, Lewis DA. The Influence of Chronic Exposure to 
Antipsychotic Medications on Brain Size before and after Tissue Fixation: A Comparison of Haloperidol and Olanzapine in Macaque Monkeys. Neuropsychopharmacology 2005: 1-13.

Ende G, Braus DF, Walter S, Weber-Fahr W, Soher B, Maudsley AA, et al. Effects of age, medication, and illness duration on the $\mathrm{N}$-acetyl aspartate signal of the anterior cingulate region in schizophrenia. Schizophr Res 2000; 41: 389-395.

Gur RE, Cowell P, Turetsky BI, Gallacher F, Cannon T, Bilker W, et al. A follow-up magnetic resonance imaging study of schizophrenia. Relationship of neuroanatomical changes to clinical and neurobehavioral measures. Arch Gen Psychiatry 1998; 55: 145-152.

Halim ND, Weickert CS, McClintock BW, Weinberger DR, Lipska BK. Effects of chronic haloperidol and clozapine treatment on neurogenesis in the adult rat hippocampus. Neuropsychopharmacology 2004; 29: 1063-1069.

Heitmiller DR, Nopoulos PC, Andreasen NC. Changes in caudate volume after exposure to atypical neuroleptics in patients with schizophrenia may be sex-dependent. Schizophrenia Res 2004; 66: 137-142.

Hirayasu Y, Tanaka S, Shenton ME, Salisbury DF, DeSantis MA, Levitt JJ, et al. Prefrontal gray matter volume reduction in first episode schizophrenia. Cereb Cortex 2001; $11: 374-381$.

Ho BC, Andreasen NC, Nopoulos P, Arndt S, Magnotta V, Flaum M. Progressive structural brain abnormalities and their relationship to clinical outcome: a longitudinal magnetic resonance imaging study early in schizophrenia. Arch Gen Psychiatry 2003; 60: 585-594.

Holcomb HH, Cascella NG, Thaker GK, Medoff DR, Dannals RF, Tamminga CA. Functional sites of neuroleptic drug action in the human brain: PET/FDG studies with and without haloperidol. Am J Psychiatry 1996; 153: 41-49.

James AC, James S, Smith DM, Javaloyes A. Cerebellar, Prefrontal Cortex, and Thalamic Volumes Over Two Time Points in Adolescent-Onset Schizophrenia. Br J Psychiatry 2004; 161: 1023-1029.

Johnston-Wilson NL, Sims CD, Hofmann JP, Anderson L, Shore AD, Torrey EF, et al. Disease-specific alterations in frontal cortex brain proteins in schizophrenia, bipolar disorder, and major depressive disorder. The Stanley Neuropathology Consortium. Mol Psychiatry 2000; 5: 142149.

Jueptner M, Weiller C. Review: does measurement of regional cerebral blood flow reflect synaptic activity? Implications for PET and fMRI. Neuroimage 1995; 2: 148156.
Kelley JJ, Gao XM, Tamminga CA, Roberts RC. The effect of chronic haloperidol treatment on dendritic spines in the rat striatum. Exp Neurol 1997; 146: 471-478.

Keshavan MS, Haas GL, Kahn CE, Aguilar E, Dick EL, Schooler NR et al. Superior temporal gyrus and the course of early schizophrenia: progressive, static, or reversible? $J$ Psychiatr Res 1998; 32: 161-167.

Konradi C, Heckers S. Antipsychotic drugs and neuroplasticity: insights into the treatment and neurobiology of schizophrenia. Biol Psychiatry 2001; 50: 729-742.

Krishnan B, Armstrong DL, Grossman RG, Zhu ZQ, Rutecki PA, Mizrahi EM. Glial cell nuclear hypertrophy in complex partial seizures. J Neuropathol Exp Neurol 1994; 53: 502-507.

Lahti AC, Holcomb HH, Weiler MA, Medoff DR, Frey $\mathrm{KN}$, Hardin $\mathrm{M}$ et al. Clozapine but not Haloperidol Reestablishes Normal Task-Activated rCBF Patterns in Schizophrenia within the Anterior Cingulate Cortex. Neuropsychopharmacology 2003a; 1: 1 .

Lahti AC, Holcomb HH, Weiler MA, Medoff DR, Tamminga CA. Functional effects of antipsychotic drugs: comparing clozapine with haloperidol. Biol Psychiatry 2003b; 53: 601-608.

Lawrie SM, Abukmeil SS. Brain abnormality in schizophrenia. A systematic and quantitative review of volumetric magnetic resonance imaging studies $B r J$ Psychiatry 1998; 172: 110-120.

Lieberman J, Chakos M, Wu H, Alvir J, Hoffman E, Robinson D et al. Longitudinal study of brain morphology in first episode schizophrenia. Biol Psychiatry 2001; 49: 487-499.

Lieberman JA, Tollefson GD, Charles C, Zipursky R, Sharma T, Kahn RS et al. Antipsychotic drug effects on brain morphology in first-episode psychosis. Arch Gen Psychiatry 2005; 62: 361-370.

Lim KO, Adalsteinsson E, Spielman D, Sullivan EV, Rosenbloom MJ, Pfefferbaum A. Proton magnetic resonance spectroscopic imaging of cortical gray and white matter in schizophrenia. Arch Gen Psychiatry 1998; 55: 346-352.

Madsen AL, Karle A, Rubin P, Cortsen M, Andersen HS, Hemmingsen R. Progressive atrophy of the frontal lobes in first-episode schizophrenia: interaction with clinical course and neuroleptic treatment. Acta Psychiatr Scand 1999; 100: 367-374.

Magistretti PJ. Cellular bases of functional brain imaging: insights from neuron-glia metabolic coupling. Brain Res 2000; 886: 108-112.

Mathalon DH, Sullivan EV, Lim KO, Pfefferbaum A. Progressive brain volume changes and the clinical course 
of schizophrenia in men: a longitudinal magnetic resonance imaging study. Arch Gen Psychiatry 2001; 58: 148157.

McDonald C, Bullmore ET, Sham PC, Chitnis X, Wickham H, Bramon E et al. Association of genetic risks for schizophrenia and bipolar disorder with specific and generic brain structural endophenotypes. Arch Gen Psychiatry 2004; 61: 974-984.

McGlashan TH, Hoffman RE. Schizophrenia as a disorder of developmentally reduced synaptic connectivity. Arch Gen Psychiatry 2000; 57: 637-648.

Miller DD, Andreasen NC, O'Leary DS, Watkins GL, Boles Ponto LL, Hichwa RD. Comparison of the effects of risperidone and haloperidol on regional cerebral blood flow in schizophrenia. Biol Psychiatry 2001; 49: 704-715.

Molina V, Gispert JD, Reig S, Pascau J, Palomo T, Martínez R et al. Olanzapine-Induced Cerebral Metabolic Changes. Relation to Symptom Changes in Schizophrenia. Int Clin Psychopharmacol 2005a; 20: 13-18.

Molina V, Gispert JD, Reig S, Sanz J, Pascau J, Santos A, et al. Cerebral metabolic changes induced by clozapine in schizophrenia. Psychopharmacology 2005b; 178: 17-26.

Molina V, Gispert JD, Reig S, Sanz J, Pascau J, Santos A, et al. Cerebral metabolism and risperidone treatment in schizophrenia. Schizophrenia Res 2003; 60: 1-7.

Molina V, Reig S, Sánchez J, Sanz J, Benito C, Pascau J et al. $\mathrm{N}$-acetyl-aspartate in the dorsolateral prefrontal region in the early years of schizophrenia are inversely related to illness duration. Schizophrenia Res 2005c: 209219.

Molina V, Reig S, Sanz J, Benito C, Pascau J, Collazos $\mathrm{F}$, et al. Association between relative frontal and temporal cortical CSF and illness duration in schizophrenia. Schizophrenia Res 2002; 58: 305-312.

Molina V, Reig S, Sanz J, Palomo T, Benito C, Sánchez $\mathrm{J}$ et al. Increase in Gray Matter Volume and Decrease in White Matter Volume in the Cerebral Cortex during Treatment with Atypical Neuroleptics in Schizophrenia. Schizophrenia Res (in press a).

Molina V, Sanz J, Sarramea F, Luque R, Benito C, Palomo T. Dorsolateral prefrontal and superior temporal volume deficits in first episode psychosis that evolve into schizophrenia. Eur Arch Psychiatry Clin Neurosci (in press b).

Molina V, Sarramea F, Sanz J, Benito C, Palomo T. Prefrontal atrophy in first episodes of schzophrenia associated with limbic hyperactivity. J Psychiatric Res 2005d: 117127.

Nair TR, Christensen JD, Kingsbury SJ, Kumar NG, Terry WM, Garver DL. Progression of cerebroventricular enlargement and the subtyping of schizophrenia. Psychiatry Res 1997; 74: 141-150.

Noh JS, Kang HJ, Kim EY, Sohn S, Chung YK, Kim SU et al. Haloperidol-induced neuronal apoptosis: role of p38 and c-Jun-NH(2)-terminal protein kinase. J Neurochem 2000; 75: 2327-2334.

Nopoulos P, Torres I, Flaum M, Andreasen NC, Ehrhardt JC, Yuh WT. Brain morphology in first-episode schizophrenia. Am J Psychiatry 1995; 152: 1721-1723.

Ongür D, Drevets WC, Price JL. Glial reduction in the subgenual prefrontal cortex in mood disorders. Proc Natl Acad Sci U S A 1998; 95: 13290-13295.

Pfrieger FW, Barres BA. New views on synapse-glia interactions. Curr Opin Neurobiol 1996; 6: 615-621.

Rajkowska G, Miguel-Hidalgo JJ, Makkos Z, Meltzer $\mathrm{H}$, Overholser J, Stockmeier C. Layer-specific reductions in GFAP-reactive astroglia in the dorsolateral prefrontal cortex in schizophrenia. Schizophr Res 2002; 57: 127-138.

Salokangas RK, Cannon T, Van Erp T, Ilonen T, Taiminen T, Karlsson H, et al. Structural magnetic resonance imaging in patients with first-episode schizophrenia, psychotic and severe non-psychotic depression and healthy controls. Results of the schizophrenia and affective psychoses (SAP) project. Br J Psychiatry 2002; 43 (Suppl): s58-s65.

Selemon LD, Goldman-Rakic PS. The reduced neuropil hypothesis: a circuit based model of schizophrenia. Biol Psychiatry 1999a; 45: 17-25.

Selemon LD, Lidow MS, Goldman-Rakic PS. Increased volume and glial density in primate prefrontal cortex associated with chronic antipsychotic drug exposure. Biol Psychiatry 1999b; 46: 161-172.

Shenton ME, Dickey CC, Frumin M, McCarley RW. A review of MRI findings in schizophrenia. Schizophr Res 2001; 49: 1-52.

Stark AK, Uylings HB, Sanz-Arigita E, Pakkenberg B. Glial cell loss in the anterior cingulate cortex, a subregion of the prefrontal cortex, in subjects with schizophrenia. Am J Psychiatry 2004; 161: 882-888.

Turetsky B, Cowell PE, Gur RC, Grossman RI, Shtasel DL, Gur RE. Frontal and temporal lobe brain volumes in schizophrenia. Relationship to symptoms and clinical subtype. Arch Gen Psychiatry 1995; 52: 1061-1070.

Uranova N, Orlovskaya D, Vikhreva O, Zimina I, Kolomeets N, Vostrikov V, et al. Electron microscopy of oligodendroglia in severe mental illness. Brain Res Bull 2001; 55: 597-610.

Uranova NA, Vostrikov VM, Orlovskaya DD, Rachmanova VI. Oligodendroglial density in the prefrontal cortex in schizophrenia and mood disorders: a study from the 
Stanley Neuropathology Consortium. Schizophr Res 2004; 67: 269-275.

Urenjak J, Williams SR, Gadian DG, Noble M. Proton nuclear magnetic resonance spectroscopy unambiguously identifies different neural cell types. J Neurosci 1993; 13: 981-989.

Volk DW, Lewis DA. Impaired prefrontal inhibition in schizophrenia: relevance for cognitive dysfunction. Physiol Behav 2002; 77: 501-505.

Wakade CG, Mahadik SP, Waller JL, Chiu FC. Atypical neuroleptics stimulate neurogenesis in adult rat brain. $J$ Neurosci Res 2002; 69: 72-79.

Wang HD, Dunnavant FD, Jarman T, Deutch AY. Effects of antipsychotic drugs on neurogenesis in the fore- brain of the adult rat. Neuropsychopharmacology 2004; 29: $1230-1238$.

Woods BT, Ward KE, Johnson EH. Meta-analysis of the time-course of brain volume reduction in schizophrenia: implications for pathogenesis and early treatment. Schizophr Res 2005; 73: 221-228.

Adress of correspondence:

V Molina, PhD

Dept of Psychiatry

Hospital Clínico de Salamanca,

Paseo de San Vicente, 58-182

37007 Salamanca

E-mail: vmolina@usal.es

SPAIN 